\title{
Noise exposure in TKA surgery; oscillating tip saw systems vs oscillating blade saw systems
}

\section{Citation for published version (APA):}

Peters, M. P., Feczko, P. Z., Tsang, K., van Rietbergen, B., Arts, J. J., \& Emans, P. J. (2016). Noise exposure in TKA surgery; oscillating tip saw systems vs oscillating blade saw systems. Journal of Arthroplasty, 31(12), 27732777. https://doi.org/10.1016/j.arth.2016.05.030

DOI:

10.1016/j.arth.2016.05.030

Document status and date:

Published: 01/12/2016

\section{Document Version:}

Accepted manuscript including changes made at the peer-review stage

\section{Please check the document version of this publication:}

- A submitted manuscript is the version of the article upon submission and before peer-review. There can be important differences between the submitted version and the official published version of record. People interested in the research are advised to contact the author for the final version of the publication, or visit the $\mathrm{DOI}$ to the publisher's website.

- The final author version and the galley proof are versions of the publication after peer review.

- The final published version features the final layout of the paper including the volume, issue and page numbers.

Link to publication

\section{General rights}

Copyright and moral rights for the publications made accessible in the public portal are retained by the authors and/or other copyright owners and it is a condition of accessing publications that users recognise and abide by the legal requirements associated with these rights.

- Users may download and print one copy of any publication from the public portal for the purpose of private study or research.

- You may not further distribute the material or use it for any profit-making activity or commercial gain

- You may freely distribute the URL identifying the publication in the public portal.

If the publication is distributed under the terms of Article 25fa of the Dutch Copyright Act, indicated by the "Taverne" license above, please follow below link for the End User Agreement:

www.tue.nl/taverne

Take down policy

If you believe that this document breaches copyright please contact us at:

openaccess@tue.nl

providing details and we will investigate your claim. 
1 Noise exposure in TKA surgery; Oscillating Tip Saw systems vs. Oscillating Blade Saw

\section{2 systems}

3

4 Peters M, $\mathrm{MSc}^{1}$, Feczko P, $\mathrm{MD}^{2}$, Tsang K, $\mathrm{MSc}^{3}$, Van Rietbergen $\mathrm{B}, \mathrm{PhD}^{2,3}$, Arts $\mathrm{J} \mathrm{PhD}^{2,3}$,

5 Emans $\mathrm{P}, \mathrm{MD}, \mathrm{PhD}^{2}$

6

$7 \quad{ }^{1}$ Department of Rheumatology, Research School CAPHRI+NUTRIM, Maastricht University 8 Medical Centre, Maastricht, The Netherlands

$9 \quad{ }^{2}$ Department Orthopaedic Surgery, Research School CAPHRI, Maastricht University Medical 10 Centre, Maastricht, The Netherlands

$11{ }^{3}$ Department Orthopaedic Biomechanics, Faculty Biomedical Engineering, Eindhoven

12 University of Technology, Eindhoven, The Netherlands 


\section{Abstract}

Background. Historically it has been suggested that noise induced hearing loss (NIHL) affects approximately $50 \%$ of the orthopaedic surgery personnel. This noise may be partially caused by the use of powered saw systems that are used to make the bone cuts. The first goal was to quantify and compare the noise emission of these different saw systems during TKA surgery. A second goal was to estimate the occupational NIHL risk for the orthopaedic surgery personnel in TKA surgery by quantifying the total daily noise emission spectrum during TKA surgery and to compare this to the Dutch Occupational Health Organization guidelines.

Methods. A conventional Sagittal oscillating blade system with a full oscillating blade and two newer oscillating tip saw systems (handpiece and blade) were compared. Noise level measurements during TKA surgery were performed during cutting and hammering, additionally surgery noise profiles were made.

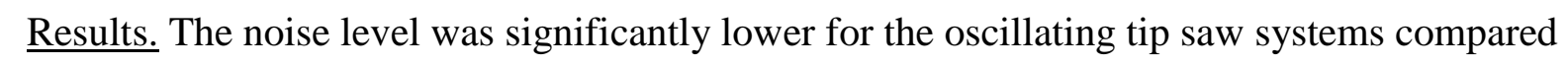
to the conventional saw system, but all were in a range that can cause NIHL. The conventional system hand piece produced a considerable higher noise level compared to oscillating tip handpiece.

Conclusion. Noise induced hearing loss is an underestimated problem in the orthopaedic surgery. Solutions for decreasing the risk of hearing loss should be considered. The use of oscillating tip saw systems have a reduced noise emission in comparison with the conventional saw system. The use of these newer systems might be a first step in decreasing hearing loss among the orthopaedic surgery personnel.

Key words: TKA surgery; hearing loss; orthopaedic theatre; saw blade; noise induced hearing loss 
Historically it has been suggested that Noise-induced hearing loss (NIHL) affects approximately $50 \%$ of the orthopaedic surgery personnel [1-3]. One study has shown that the operation theatre of the department of Orthopaedic Surgery was subject to the loudest noises in a hospital [4]. This is partly caused by the noise generated from the powered bone saws during bone cutting [5-10]. Another factor is the hammering used to position implants, which is associated with very high impact peak noises [5-10]. A combination of these two different types of noise is a major cause for the high incidence of NIHL among the orthopaedic surgery personnel [3].

Bone saws are available in different design concepts (fig. 1a). The current conventional design features a fully oscillating blade shaft (fig. 1a, upper). A newer design features an oscillating tip powered through an internal mechanism of a stationary, hollow shaft (fig. 1a, middle and lower). Since the bony cuts in total knee arthroplasty (TKA) are often made by guiding the blade shaft through a slot in a metal guiding block, one of the proposed advantages of the latter design is a lower noise emission due to decreased blade-block interaction with less chance for soft tissue damage. However, no quantitative acoustic information from this new saw blade design is available from a clinical setting.

Sydney et al. (2007) have performed noise measurements in a laboratory setting, using both a conventional oscillating blade saw and an oscillating tip saw in simulated TKA surgeries on porcine knees [11]. Although they concluded that the oscillating tip saw featured reduced noise exposure in their experiment, different factors may have influenced their results compared to regular TKA surgeries on human patients. In particular, differences in working place environment and the properties of cadaveric porcine bone may have affected the results.

The first goal of this study therefore was to quantify and compare the noise emission of these different saw systems (blade and hand piece) when used in a standard operating room during TKA surgery. Our hypothesis is that the newer oscillating tip saw systems produce significantly less noise during cutting than the conventional oscillating blade saw system. A second goal was to estimate the occupational NIHL risk for the orthopaedic surgery personnel in TKA surgery by quantifying the total daily noise emission spectrum, also including impact noises due to hammering, during TKA and to compare this to the Dutch Occupational Health 
73 Organization (ARBO) guidelines. 


\section{Materials \& Methods}

\section{Bone saw instruments}

A conventional Sagittal oscillating blade saw (Dual-Cut, Stryker, Michigan, USA) and two oscillating tip saws (Precision Saw and Falcon Blade, Stryker, Michigan, USA) were selected for comparison in this study (fig. 1a). The Stryker System 5 hand piece with built-in motor unit was used to power the Sagittal oscillating blade saws. The oscillating tip saws were powered by a newer Precision hand piece system 7 .

Therefore, 3 different saw systems were examined during cutting: (I) Sagittal oscillating blade saw with System 5 hand piece (SAG), (II) Precision Saw with Precision hand piece system 7 (PRE), and (III.) the Falcon Blade with Precision hand piece system 7 (FAL). In addition, the System 5 and system 7 hand pieces alone were examined on noise emission. Different types of cuts were made during each TKA surgery: the tibia cut, the distal femur cut, and the 4-in-1 chamfer cut. For each cut, the same type of closed-slot metal cutting block (Scorpio, Stryker, Michigan, USA) was used to ensure guidance of the blade when cutting through the bone.

\section{Measuring noise levels}

Four different kinds of noise measurements were performed in this study: measurements of the saw systems during cutting and of the hand piece alone (2.1), TKA surgery noise profiles (2.2), and impact noise measurements during metal-on-metal hammering (2.3). All these noise measurements were performed with a calibrated sound level meter (2260 Investigator, Brüel \& Kjær, Narum, Denmark). When used, the sound level meter was calibrated daily and has a measurement error of $<0.1 \mathrm{~dB}$. The three different measurements are explained separately below.

All measurements were carried out during TKA surgeries. All cuts during surgery were performed by two experienced surgeons, both skilled in all saw systems used. Inclusion criteria were patients with primary osteoarthritis requiring total knee replacement surgery. Excluded were patients with diseases that could negatively impact bone quality (osteoporosis, Paget disease, multiple myeloma, malignant bone tumors and rheumatoid arthritis).

\subsection{Saw blade cutting measurements}

During the tibia cut, distal femur cut and 4-in-1 chamfer cut in TKA surgery, the sound level meter was held over the shoulder of the surgeon, with the microphone tip next to the 
surgeon's ear while pointing towards the sound source at approximately 40 centimetres

109 distance from the noise source (fig. 1b). This ensured that representative measurements were 110 obtained while maintaining surgical sterility. In addition, measurements of the hand pieces 111 alone were performed at approximately 40 centimetres distance from the noise source. In this 112 way an estimation of the influence of the hand piece on the total noise emission of the saw 113 system during cutting can be made.

115 During cutting the noise levels were measured on an A-weighted scale. This is a logarithmic 116 measure of the measured sound intensity in comparison to a reference level, which is set to 117 the threshold of human hearing, $I_{0}=10^{-12}\left[\mathrm{~W} / \mathrm{m}^{2}\right]$. The A-weighted scale $(\mathrm{dB}(\mathrm{A}))$ closely 118 reflects the loudness perceived by the human ear.

120 In order to check whether potential hearing loss in the range of normal speech would be 121 expected, full frequency spectra were measured for a limited number of cases: 9 frequency 122 spectra for PRE, 6 for SAG and 4 for FAL. Analyses were performed in line with Sydney et 123 al. [11].

The selection of used saw type was randomized for each patient.

\subsection{TKA surgery profile measurements}

128 The ARBO guidelines state that during an 8-hour working day the averaged noise level $\left(L_{\text {Aeq, }}\right.$ shour) should be below $85 \mathrm{~dB}(\mathrm{~A})$ while a noise level below the $80 \mathrm{~dB}(\mathrm{~A})$ is recommended [12]. The $L_{\text {Aeq, shour }}$ is a good measure of a subject's daily occupational noise exposure [12].

131 Therefore entire TKA surgery profiles were made to calculate the $L_{\text {Aeq, }}$, shour which includes all 132 noises generated in TKA surgeries.

134 Four noise profiles of TKA surgeries were measured at 1.4 meter distance of the saw system 135 (fig. 1b). This was the closest distance where the sterility could be maintained, while keeping 136 the noise level meter at a constant distance. Noise measurements of 10 seconds on an A137 weighted scale were made, creating an entire TKA surgery noise profile with discrete steps of 13810 seconds. The measurements were started at incision and stopped when the wound in the 139 knee was closed. It was ensured that no one was standing between the sound source and the 140 sound level meter. Given the length of the measurement, TKA surgery profiles were only 141 performed for SAG and FAL, which were found to be the noisiest and most quiet saw systems 
142 respectively. For both cases the measurements were performed twice after which the values

143 were averaged.

144

\subsection{Impact noise measurements}

146 The ARBO guidelines also state that peak noises with a C-weighting $\left(L_{C, \text { peak }}\right)$ should be

147 below the $140 \mathrm{~dB}(\mathrm{C})$ and they recommend the $L_{C \text {, peak }}$ to be below the $135 \mathrm{~dB}(\mathrm{C})$ [12]. It is

148 also known that the pain threshold is already at $120 \mathrm{~dB}(\mathrm{C})$ [11]. Therefore the impact (peak)

149 noises of the metal-on-metal hammering are measured separately on a C-weighted scale. This

150 was performed during hammering of the 4-in-1 chamfer block, femur box and tibial tray

151 component onto the bone. These measurements were measured at ear distance ( 0.4 meter)

152 from the noise source (fig. 1b).

153

3. Noise quantification

155

\subsection{Averaging of noise levels}

156 The average noise levels and their standard deviation (SD) per saw system were calculated.

157 This was done by first calculating the sound intensities $I\left[\mathrm{~W} / \mathrm{m}^{2}\right]$ from the measured A-

158 weighted noise levels $L_{A}[\mathrm{~dB}(\mathrm{~A})]$ using:

159

160

$$
\mathrm{I}=\mathrm{I}_{0} * 10^{\left(\mathrm{L}_{\mathrm{A}} / 10\right)}
$$

161

162 After averaging these intensities, an average A-weighted decibel scale was determined using 163 the inverse relationship:

164

$$
\mathrm{L}_{\mathrm{A}}=10 *{ }^{10} \log \left(\mathrm{I} / \mathrm{I}_{0}\right)
$$

\subsection{TKA surgery profile measurements}

168 During the four entire TKA surgery measurements, noise measurements of 10 seconds were made at a constant distance of 1.4 meter of the patient's knee (fig 1b). A distance correction was performed for the measurements during hammering or cutting of the surgeon, to ensure the measurements are representative to the surgeon's ear. This was done by again first calculating the sound intensity using equation 1 . The sound intensities during hammering or cutting then were corrected for the longer distance using

$$
\mathrm{I}_{\text {corrected }}=\left(\mathrm{r}_{\text {requested }} / \mathrm{r}_{\text {actual }}\right)^{2} * \mathrm{I}
$$


177 with $r_{\text {requested }}=0.4[\mathrm{~m}]$ the required distance and $r_{\text {actual }}=1.4[\mathrm{~m}]$ the actual measurement

178 distance. From these corrected and non-corrected intensities the average sound intensity was

179 calculated and converted back again using equation 2.

180

181 The equivalent noise level over 8 hours, $L_{A e q}$, shour is calculated for the entire TKA surgery

182 profiles according to [12]:

183

184

$$
\mathrm{L}_{\text {Aeq, } 8 \text { hour }}=\mathrm{L}_{\text {Aeq, corrected }}+10 *{ }^{10} \log \left(\mathrm{T}_{\mathrm{h}} / 8\right)
$$

185

186 With $T_{h}$ the actual time $[\mathrm{h}]$ a subject is subjected to the noise. The $L_{A e q}$, 8hour is parameter 187 reflects a subject's daily occupational noise exposure [12]. It was further assumed that 3 to

188 maximum 5 operations per day are performed and that the average operation time would be

18990 minutes, leading to a total operation time $T_{h}$ of 4.5 to 7.5 hours.

190

\subsection{Impact noise measurements}

192 The average impact noise $\left(L_{C e q}\right)$ was calculated in the same as described in the previous

193 paragraph for $L_{A e q}$.

194

195

196 Statistical analysis was performed with SPSS software (19.0; SPSS inc., Chicago, Illinois)

197 and Microsoft Excel 2007. P-values were obtained by non-parametric tests, Mann-Whitney

198 for 2 sample comparisons and Kruskall-Wallis for multiple sample comparisons, due to the

199 logarithmic decibel scale. Statistical significance was reached when $p<0.05$. As described in

200 the previous section, the averages and standard deviations were computed by first calculating

201 the sound intensities on a linear scale. From this linear scale the average and standard

202 deviation were taken and again calculated to the $\mathrm{dB}$ scale. 


\section{Results}

205 A total of 108 patients were included, 44 in the SAG group, 33 in the PRE group and 31 in the 206 FAL group.

207

\section{Saw blade cutting measurements}

209 The cutting blocks used for each cut had little influence on the noise level (Kruskal-Wallis, $210 \mathrm{p}=0.550$ ). Therefore, it was chosen not to differentiate between the different cuts for further 211 analysis. In figure $2 \mathrm{a}$ the different saw systems and their noise levels are shown. Shown is that 212 there are significant differences between the SAG vs. PRE and SAG vs. FAL (both Mann213 Whitney, $\mathrm{p}<0.001$ ). Also a significant difference between PRE and FAL was found (Mann-

214 Whitney, $\mathrm{p}<0.001)$. It should be noted that the noise level for all saw systems and all cuts 215 exceeds $75 \mathrm{~dB}(\mathrm{~A})$, which is regarded as potentially hazardous for some individuals in case of 216 regular exposure [13]. Figure $2 b$ shows a significant difference between the noise levels of the 217 two hand pieces System 5 and System 7 (Mann-Whitney, p=0.008).

Figure 3 shows the frequency spectra that were made of the different saw systems during the surgery cuts. The frequency interval of human speech spans approximately the region of 400$5000 \mathrm{~Hz}$. One can see that for all saw systems the main contribution to the total noise is in this region.

$\underline{\text { TKA surgery noise profiles }}$

225 The average noise levels during four entire surgeries was measured for FAL $(n=2)$ and SAG $226(n=2)$. The calculated noises of a surgery with the use of SAG exceeded the noise with the use of FAL, respectively $83.7 \mathrm{~dB}(\mathrm{~A})$ and $80.0 \mathrm{~dB}(\mathrm{~A})$. The daily exposure level $\left(L_{\text {Aeq, }}\right.$, shour $)$ for 3 TKA surgeries, taking $90 \mathrm{~min}$ as an estimated average surgery time, is then $81.2 \mathrm{~dB}(\mathrm{~A})$ and $77.5 \mathrm{~dB}(\mathrm{~A})$ for respectively $\mathrm{SAG}$ and FAL. The SAG is then above the ARBO recommendation of $L_{\text {Aeq, }}$, shour $<80.0 \mathrm{~dB}(\mathrm{~A})$.

232 Impact noise measurements

233 The impact noise measurements are shown in table 1. All peak noises comply with the ARBO 234 recommendation of a maximum value of $135 \mathrm{~dB}(\mathrm{C})$. However, it is known that the pain 235 threshold of hearing is about $120 \mathrm{~dB}(\mathrm{C})$, all average peak noises exceeded this threshold [11]. 
238 The first goal of this study was to quantify and compare the noise emission of a conventional oscillating blade saw systems (SAG) and two oscillating tip saw systems (PRE and FAL) in a realistic clinical environment.

As expected, the conventional oscillating blade saw system produced significantly more noise compared to the newer oscillating tip saw systems with an absolute difference around 10 $\mathrm{dB}(\mathrm{A})$. This difference can be explained by two aspects. First, the new design of oscillating tip blades reduces the noise by a decreased interaction of the moving blade with the saw block. Second, the newer system 7 hand piece is more quiet than the system 5 hand piece as shown in this study.

The average measured noise levels during cutting always exceeded the $75 \mathrm{~dB}(\mathrm{~A})$ threshold for all saw systems. This is a level that for some individuals might cause hearing loss when being regularly exposed [13]. Since the conventional oscillating blade saw systems exceeded this level by a wider margin than the oscillating tip saw systems, it is inferred that the use of conventional oscillating blade saw systems is more likely to generate NIHL for the

254 orthopaedic surgery personnel.

Our findings are in line with the study of Sydney et al. [11]. Although the measured noise levels in their study were lower than in our study, they also concluded that the newer oscillating tip saw systems produce significantly less noise than the conventional oscillating blade saw systems. The reason for the lower noise emission in the study of Sydney et al. could relate to the use of porcine tibias and femurs, but it could also relate to the acoustic properties of the room in which the measurements were performed.

A second goal of our study was to estimate the occupational NIHL risk for the orthopaedic surgery personnel in TKA surgery by quantifying the total daily noise emission spectrum and to compare this to the ARBO guidelines. The TKA surgery noise profiles revealed that the average noise produced during TKA surgery is higher when using the SAG saw system than using the FAL saw system. In addition to the noise generated by the saw, the metal-on-metal hammering causes peak noises in the range of the pain threshold [11]. For a total of 3 TKA surgeries during one day the noise levels are still below the ARBO limit of $L_{\text {Aeq, }}$,hour $<85$ $\mathrm{dB}(\mathrm{A})$, but the SAG may exceed the ARBO recommendation of $L_{\text {Aeq, }}$, 
271 However, the tensor tympani muscle reflex is not fast enough to protect the ear from peak

272 impact noises [14]. Therefore, impact noises may cause instant hearing damaging. Our TKA

273 surgery profile analyses do not take this extra burden into account and therefore our results

274 may still be an underestimation of the actual burden to hearing. Our findings are in line of

275 those found by Love et al. [5], who found comparable values for the average noise produced

276 during TKA surgery. Both are in the range of the pain threshold of hearing. The metal-on-

277 metal peak noise level found in their study $(145.5 \mathrm{~dB}(\mathrm{C}))$, however was higher than found in

278 our study $(131.0 \mathrm{~dB}(\mathrm{C}))$ and would also exceed the ARBO limit of $140 \mathrm{~dB}(\mathrm{C})$.

280 Surgeons should be aware that NIHL is a major problem in the orthopaedic theatre and that

281 they should especially protect the orthopaedic surgery personnel from the loud noises

282 produced during TKA surgery [1-3]. We therefore recommend the use of the newer

283 oscillating tip saw systems, preferably FAL, which may reduce the NIHL risk in the operating

284 theatre. This is especially recommended if more than 3 surgeries are performed during one 285 day.

Several articles recommend hearing protection for orthopaedic surgeons [1-3]. However, in practice, surgeons have many objections against hearing protection. Most importantly, it impedes verbal communication with his colleagues in the operation theatre. However from a NIHL protection standpoint they should be advocated.

292 A limitation of the study is that the TKA surgery profiles were only measured twice with the 293 SAG and FAL. No surgery profiles were made with PRE. However, since the SAG and the 294 FAL system form the upper and lower limit on the noise production, it is to be expected that 295 the results for the other systems are in between these values.

\section{Conclusion}

298 Noise induced hearing loss is an underestimated problem in the orthopaedic surgery.

299 Solutions for decreasing the risk of hearing loss should be considered. The use of oscillating 300 tip saw systems have a reduced noise emission in comparison with the conventional saw 301 systems. The use of these newer saw systems might be a first step in decreasing hearing loss 302 among the orthopaedic surgery personnel. 


\section{References}

305

1. Holmes Jr GB, Goodman KL, Hang DW et al., Noise levels of orthopedic instruments and their potential health risks. Orthopedics 1996;19:35.

2. Kamal SA, Orthopaedic theatres: a possible noise hazard? J Laryngol Otol 1982;96:985.

3. Willett KM, Noise-induced hearing loss in orthopaedic staff. J Bone Joint Surg Br 1991; 73:113.

4. Ilene J. Busch-Vishniac, James E. West et al., Noise levels in Johns Hopkins Hospital. J. Acoust. Soc. Am. 2005 Volume 118, Issue 6, pp. 3629-3645

5. Love $\mathrm{H}$, Noise exposure in the orthopaedic operating theatre: a significant health hazard. ANZ J Surg 2003; 73:836.

6. Dodenhoff RM, Noise in the orthopaedic operating theatre. Ann R Coll Surg Engl 1995;77(Suppl 1):8.

7. Ullah R, Bailie N, Crowther $\mathrm{S}$ et al., Noise exposure in orthopaedic practice: potential health risk. J Laryngol Otol 2004;118:413.

8. Mullett H, Synnott K, Quinlan W, Occupational noise levels in orthopaedic surgery. Ir J Med Sci 1999;168:106.

9. Nott MR, West PD, Orthopaedic theatre noise: a potential hazard to patients. Anaesthesia 2003;58:784.

10. Siverdeen Z, et al., Exposure to noise in orthopaedic theatres - do we need protection? Int. J of Clin Pract, 2008;1720:1722

11. Sydney SE, Lepp AJ et al., Noise Exposure Due to Orthopedic Saws in Simulated Total Knee Arthroplasty Surgery. J of Arthroplasty Vol. 22 No. 8 2007;1193:1197

12. Staatsblad 2006:56 Arbeidsomstandighedenbesluit

13. Moore BCJ, Cochlear Hearing Loss, (2007) Chichester: Wiley \& Sons Ltd.

14. Saladin, Kenneth - the unity of form and function ( $6^{\text {th }}$ ed.). Anatomy and physiology. p. 601 . 